\title{
Surgical versus percutaneous
} isolated pelvic perfusion (IPP) for advanced melanoma: comparison in terms of melphalan pharmacokinetic pelvic bio-availability

\author{
Stefano Guadagni ${ }^{*} \mathbb{0}$, Giancarlo Palumbo ${ }^{2}$, Giammaria Fiorentini ${ }^{3}$, Marco Clementi², Luca Marsili', \\ Aldo Victor Giordano ${ }^{1}$, Francesco Masedu ${ }^{1}$ and Marco Valenti ${ }^{1}$
}

\begin{abstract}
Background: Isolated pelvic perfusion (IPP) can be used to treat unresectable melanoma metastases of the pelvis. IPP can be performed either by surgical or percutaneous approaches, using different balloon catheters. The aim of this study was to examine whether the surgical and percutaneous approaches were comparable with respect to tumor drug exposure in the pelvis.

Methods: A pharmacokinetic study was performed in 5 melanoma patients treated with surgical IPP and five with percutaneous IPP. Both groups received melphalan at the dose of $30 \mathrm{mg} / \mathrm{m}^{2}$. Melphalan pharmacokinetic analyses were performed and the main parameter used to evaluate pelvic tumor drug-exposure was the ratio of areas under the melphalan plasma concentration curves in the pelvis and the systemic compartment, during the perfusion time $\left(A \cup C_{0 \text { to } 20}\right.$ ). Non-parametric Mann-Whitney tests were employed for statistical comparisons.

Results: The median and interquartile range (IQR) values of the ratios between melphalan $A_{U} C_{0}$ to 20 in pelvic and systemic compartments were 7.9 (IQR 7.2 to 9.9) and 5 (IQR 4 to 7.9) for surgical and percutaneous IPPs, respectively $(p=0.209)$.

Conclusions: Tumor exposure to drug using these two methods did not statistically differ and both methods, therefore, can be adopted interchangeably, utilizing a perfusion blood flow rate of approximately $120 \mathrm{ml} / \mathrm{min}$. The small sample size is a limitation of this study but our preliminary results can be used to calculate the effect size of a larger trial.
\end{abstract}

Trial Registration Clinical Trials.gov Identifier NCT01920516; date of trial registration: August 6, 2013

Keywords: Melphalan, Isolated pelvic perfusion, Melanoma

\section{Background}

Regional chemotherapy is an option for relapsed patients with advanced cancers in the pelvic and groin areas. In the 1950s [1-3], surgeons developed isolated pelvic perfusion (IPP), with the purpose of isolating the pelvic circulation by blocking blood-flow in the aorta and inferior

\footnotetext{
*Correspondence: stefano.guadagni@univaq.it

1 Department of Applied Clinical Sciences and Biotecnology, University of L'Aquila, via Vetoio, 67100 L'Aquila, Italy

Full list of author information is available at the end of the article
}

vena cava with balloon catheters and at the level of the thigh with pneumatic cuffs, with the pelvic area subsequently perfused with antineoplastic drugs via extracorporeal blood circulation. Indeed, several IPP techniques have been published [4] and a subsequent pharmacokinetic study demonstrated that there is drug leakage from the pelvic compartment [5]. Improvements in procedure to reduce morbidity and side-effects include a simplified technique, called hypoxic pelvic perfusion, based on the use of two balloon catheters positioned by femoral vessel 
exposure [6]. This technique is similar but simpler to that of Turk et al. [7], which involves the use of four catheters. Aigner's technique [6] has now been fully evaluated by van Ijken et al. $[8,9]$ in both animals and humans, in terms of feasibility, pharmacokinetics, adverse events and clinical outcomes. Further significant improvements were reported using a percutaneous hypoxic IPP technique proposed by Thompson et al. [10]. This technique, characterized by the use of 18 -French (Fr.) introducers [11], has been further improved by Ricci et al., using 11-Fr. introducers [12]. A percutaneous approach employing two cannula sheaths was reported by Bonvalot et al. [13], whereas Begossi et al. [4] and more recently Murata et al. [14] used four cannula sheaths (two 9-Fr. and two 6-Fr.). Hemofiltration, used at the end of IPP to reduce the drug-related side effects, has been shown to be a safe and effective procedure $[5,15,16]$.

The surgical method that exposes femoral vessels is recommended when lymphadenectomy is required but is rarely repeatable due to the formation of scar tissue. The percutaneous approach is, therefore, more feasible in patients that require repeated IPPs to prolong clinical response and survival [14].

To date, no reports have compared surgical and percutaneous approaches with respect to pelvic tumor drug exposures. Therefore, we have tested the hypothesis that pelvic tumor drug exposure would be similar using different catheters under conditions of similar blood flow rates in a pharmacokinetic study performed on 10 patients with loco-regional melanoma metastases to pelvic and/or groin regions, employing hypoxic IPP delivering of Melphalan, with subsequent hemofiltration to reduce sideeffects (Additional file 1).

\section{Methods}

\section{Eligibility criteria}

This interventional pilot study has been performed in accordance with the Declaration of Helsinki and has been approved by the ethics committee of University of L'Aquila, L'Aquila, Italy, as part of a larger study (ClinicalTrials.gov Identifier NCT01920516). Written informed consent was obtained from each of the 10 patients, presenting with loco-regional melanoma metastases to the pelvis and or inguinal region, after receiving complete information concerning their disease and the implications of the proposed palliative treatment, in accordance with the ethical standards of L'Aquila University committee on human experimentation.

Patients (Table 1) included in the study had stage IIIC melanoma [17], life expectancy $>3$ months, and a Karnofsky performance scale index of $>60$ [18]. Patients with metastases in the lower part of the thigh, extrapelvic metastases, renal and liver failure, deep venous thrombosis, severe atherosclerosis or coagulopathy, were excluded from this study. Before perfusion, all patients were subjected to angiography or angio-CT of the aorto-iliac tree and inferior vena cava. Limitations included: (1) no percutaneous perfusion when common femoral artery diameter was $\leq 7 \mathrm{~mm}$, making vessel dissection risky; (2) when surgical procedures performed previously had resulted in femoral vessels fibrosis, exposure of iliac vessels was necessary. Demographic data (Table 1) was collected by the medical team during operative procedures and recovery.

\section{Hypoxic pelvic perfusion techniques}

Perfusions were performed under general anesthesia, as previously described [15]. Hypoxic perfusion with hemofiltration has three phases: the first, the isolation phase, is characterized by the blockage of blood flow to the aorta and inferior cava, using endovascular balloon catheters, at the level of the thighs by pneumatic cuffs and can be performed by both surgical or percutaneous methods (Fig. 1).

In the surgical approach, following systemic heparinization (150 U/kg heparin), a 3-lumen, 12-Fr. balloon catheter (pfm medical ag, Cologne, Germany) was introduced into the inferior vena cava via the saphenous vein (or iliac vein) and into the aorta via the femoral artery (or iliac artery). Catheters are positioned below renal vessels but above aortic and venous bifurcations, using a fluoroscopically guided wire. One of the three lumens of the catheter (Fig. 2a) is used for blood circulation and the other lumens used for inflating balloons and positioning the guide wire.

In the percutaneous procedure, femoral vessels were punctured using two 11-Fr. introducers, each with a hemostatic valve and dilatator (Radifocus; Terumo, Tokyo, Japan): (1) an arterial introducer of $25 \mathrm{~cm}$ length

Table 1 Sample timing

\begin{tabular}{|c|c|c|c|c|c|c|c|c|c|c|}
\hline \multirow{2}{*}{$\begin{array}{l}\text { Sampling site } \\
\text { Pelvic (inferior cava vein) }\end{array}$} & \multicolumn{10}{|c|}{ Sampling time (min) } \\
\hline & 5 & 7 & 14 & 17 & 20 & & & & & \\
\hline Systemic (periferal vein of the arm) & 5 & 7 & 14 & 17 & 20 & 25 & 30 & 45 & 60 & 80 \\
\hline Blood exiting patients via extracorporeal circuit & & & & & & 25 & 30 & 45 & 60 & 80 \\
\hline Ultrafiltrate & & & & & & 25 & 30 & 45 & 60 & 80 \\
\hline
\end{tabular}




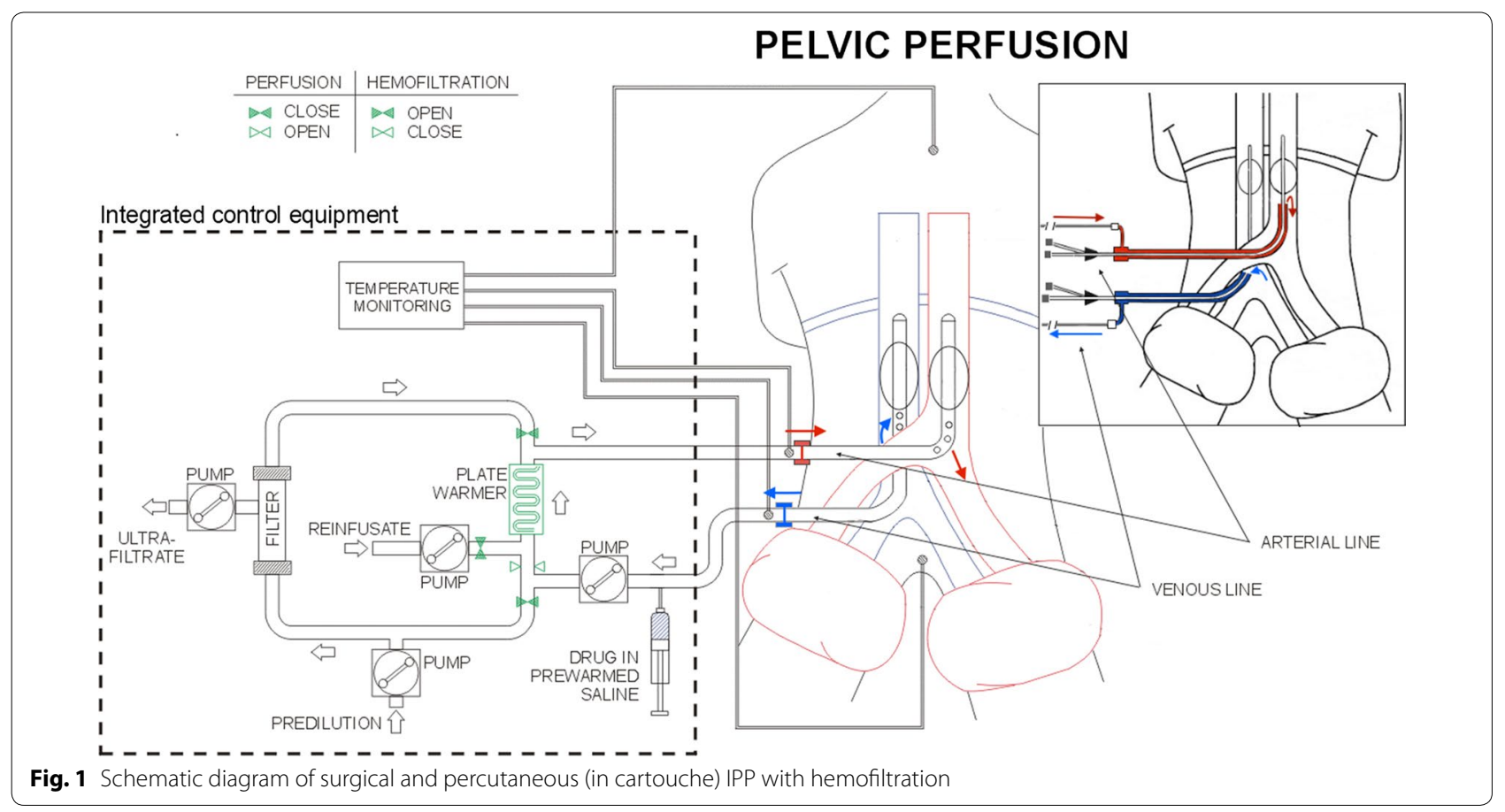

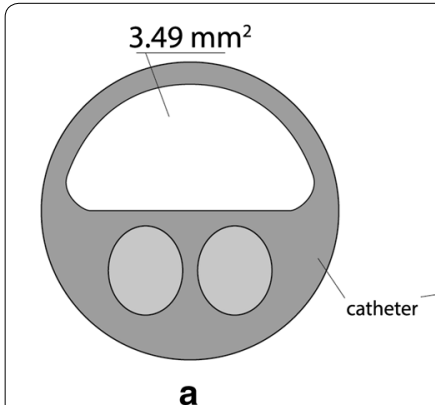

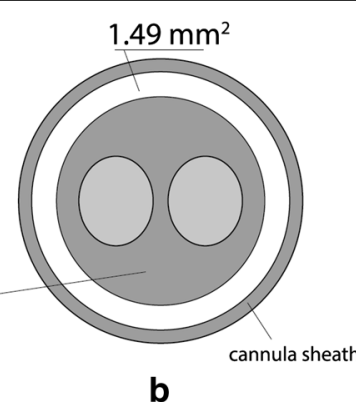

Fig. 2 Cross sections of a 3-lumen, 12-Fr. balloon catheter; $\mathbf{b}$ 2-lumen, 8-Fr. balloon catheter and 11-Fr. cannula sheath introducer (the blood flows in the white area)

and (2) a venous introducer of $10 \mathrm{~cm}$ length, and 2 double-lumen 8-Fr. balloon catheters (pfm medical ag) were inserted, each with one lumen utilized to inflate the balloon and the other to position the guide wire. Blood circulation and drug perfusion was accomplished in the long, hollow cylindrical space between the introducer wall and the catheter, with blood flowing through a ring surface at the top of the space (Fig. 2b).

In order to suspend blood flow, balloons were inflated with radiopaque diatrizoate dye diluted in an isotonic sodium chloride solution. Immediately prior to the initiation of perfusion, in order to complete pelvic circulation isolation, two large-cuff orthopedic tourniquets were positioned around each thigh and inflated.
The second phase, the perfusion phase, is characterized by extracorporeal blood circulation. Infusion channels of arterial and venous surgical catheters or hemostatic valve channels of the 11-Fr. introducers were connected to a hypoxic perfusion tube set mounted on a regional, cancer therapy-dedicated, circulation device (Performer LRT; RanD, Medolla, Italy). The circuit was primed with an isotonic sodium chloride solution containing heparin $(10,000 \mathrm{U} / \mathrm{l})$. Drug perfusion was initiated upon establishing the required blood flow rate of approximately $100 \mathrm{ml} /$ min in the extracorporeal circuit (aspiration from the inferior cava vein and infusion into the aorta). Melphalan $\left(30 \mathrm{mg} / \mathrm{m}^{2}\right)$, diluted in $250 \mathrm{ml}$ of an isotonic sodium chloride solution containing $16 \mathrm{mg}$ of dexamethasone sodium phosphate, was administered via the circuit over a 3-min period. The extracorporeal circuit (Fig. 1) connected to the circulation device contains a heating element and a hemofiltration module, both of which were controlled by the device during perfusion and subsequent hemofiltration phases and perfusion was continued for $20 \mathrm{~min}$. Temperature loss approximated to $1{ }^{\circ} \mathrm{C} / \mathrm{m}$ of tubing and the length of the tubing was $5 \mathrm{~m}$. Therefore, to ensure normothermia, a temperature of $42{ }^{\circ} \mathrm{C}$ was required at the heating element outlet port. The circulation device has built in sensors and monitors to regulate and monitor blood flow, withdrawal pressure, infusion pressure, circuit and patient temperatures, hemofiltration parameters, and has also data storage capacity. 
The third phase, the hemofiltration phase, follows perfusion, was characterized by deflation of the catheter balloons and pneumatic cuffs and the restoration of normal circulation. Hemofiltration was then administered for $60 \mathrm{~min}$ via the circuit. Blood flow was increased to $200 \mathrm{ml} / \mathrm{min}$ and maintained at the aorta withdrawal site and the temperature at the outlet level of the heating element was reduced to $39{ }^{\circ} \mathrm{C}$. A polyamide hemofilter of $2.1 \mathrm{~m}^{2}$ (RanD, Medolla, Italy) surface area was used for filtration, after which catheters were withdrawn and vessels repaired. Following percutaneous protocol, compression hemostasis was applied for $\sim 30 \mathrm{~min}$. Protamine was then injected $(200 \mathrm{IU} / \mathrm{kg})$ to reverse the anticoagulant effects of heparin.

\section{Melphalan regimen and pharmacokinetic study}

Melphalan was administered at the dose of $30 \mathrm{mg} / \mathrm{m}^{2}$, according to previous reports $[16,19,20]$ and hemofiltration was performed in all procedures. Pharmacokinetic studies were performed on 5 patients submitted for surgical procedure and five for the percutaneous procedure. For sample collection and analysis, pelvic (inferior cava vein) and systemic (peripheral vein of the arm) blood samples were obtained during perfusion at 5,7 , 14, 17, and $20 \mathrm{~min}$. At the end of perfusion and following balloon deflation, samples of systemic blood, blood exiting patients via the extracorporeal circuit, and ultrafiltrate at $25,30,45,60$, and $80 \mathrm{~min}$ time points were also collected (Table 1). All samples were processed and stored immediately. Blood samples were centrifuged at $3000 \mathrm{rpm}$ for $10 \mathrm{~min}$, plasma transferred to capped polypropylene tubes and stored at $-20{ }^{\circ} \mathrm{C}$. High-performance liquid chromatography (HPLC) analysis of melphalan concentration was performed within $24 \mathrm{~h}$ of collection precisely according to the method Mirkou et al. [21]. For pharmacokinetic studies, non-compartment pharmacokinetic analysis (iv infusion NCA model) of melphalan concentrations, with respect to time, were obtained using PK Solver computer software, written in Visual Basic for Applications (VBA) [22]. For hemofiltration (20 to $80 \mathrm{~min}$ ), total melphalan removal (TMR) was calculated from the ratio of melphalan concentrations in ultrafiltrate and blood exiting the patient. $\mathrm{pH}$ and $\mathrm{pO}_{2}$ were also measured in blood samples collected from the extracorporeal circuit at 5, 7, 14, 17, and 20 min, during the isolated perfusion phase, using a blood gas analyzer (ABL800 FLEX, Radiometer, Brønshøj, Denmark).

\section{Statistical analysis}

Statistical comparisons between surgical and percutaneous treatments in pharmacokinetics, biochemical and hemodynamic parameters were performed using the non-parametric Mann-Whitney test with the type I error set at 0.05 . Median and IQR have been reported. The statistical software STATA (Version 14) was used in this study.

\section{Results}

Patient groups did not exhibit significant differences in age, weight, height and operative times (Table 2). Patients required a median of 10 days post-surgical recovery (IQR 7 to 10$)$. This was significantly longer $(p=0.043)$ than the time required for recovery following the percutaneous procedure, with a median of 6 days (IQR 5 to 6 ).

Table 3 reports median and IQR blood flow values, withdrawal pressures, infusion pressures, rectal and esophageal temperatures registered during perfusion. The sample included 10 different patients, five submitted for the surgical procedure and five for the percutaneous procedure. Median blood flow values were not significantly different between the 2 groups $(p=0.754)$, and approximated to $100 \mathrm{ml} / \mathrm{min}$. The two techniques did not show other statistically significant differences (Table 3).

Table 2 Demographic data

\begin{tabular}{llll}
\hline Groups & Surgical & Percutaneous & MW (p value) \\
\hline Gender & & 2 & \\
$\quad$ Male & 3 & 3 & 68 (IQR 68 to 72) \\
$\quad$ Female & 2 & 73 (IQR 72 to 76) & 0.175 \\
Age (years), median (IQR) & 52 (IQR 51 to 60) & 171 (IQR 169 to 172) & 0.209 \\
Weight (kg), median (IQR) & 72 (IQR 71 to 73) & & 0.461 \\
Height (cm), median (IQR) & 169 (IQR 164 to 172) & 5 & \\
Histology & & 131 (IQR 130 to 156) & 0.602 \\
$\quad$ Epithelioid pattern & 5 & 6 (IQR 5 to 6) & 0.043 \\
Operative time (min), median (IQR) & 132 (IQR 126 to 145) &
\end{tabular}


Table 3 Comparison of the two techniques during the IPP $(20 \mathrm{~min})$ based on hemodynamic and biophysical parameters

\begin{tabular}{|c|c|c|c|c|c|}
\hline \multirow[t]{2}{*}{ Technique } & \multicolumn{2}{|l|}{ Surgical } & \multicolumn{2}{|c|}{ Percutaneous } & \multirow{2}{*}{$\begin{array}{l}\text { MW } \\
\text { p value }\end{array}$} \\
\hline & Median & IQR & Median & IQR & \\
\hline Blood flow (ml/min) & 112.5 & (111.5 to 120.5$)$ & 120 & (103.5 to 124.5$)$ & 0.754 \\
\hline Withdrawal pressure $(\mathrm{mmHg})$ & -20 & $(-25$ to -8$)$ & -37 & $(-98$ to -35$)$ & 0.076 \\
\hline Infusion pressure (mmHg) & 101 & (94 to 111.5 ) & 114 & (109.5 to 120$)$ & 0.251 \\
\hline Rectal temperature $\left({ }^{\circ} \mathrm{C}\right)$ & 37.5 & (36.8 to 37.7 ) & 37.5 & (37 to 37.8 ) & 0.602 \\
\hline Esophageal temperature $\left({ }^{\circ} \mathrm{C}\right)$ & 36 & (35.5 to 36.2$)$ & 36.5 & (35.7 to 36.4 ) & 0.462 \\
\hline
\end{tabular}

MW Mann-Whitney test

In the pharmacokinetic study, in order to compare surgical and percutaneous procedures, the ratios between the area under the plasma concentrations time curve (AUC $_{0 \text { to } 20}$ corresponding to the hypoxic perfusion time) of the pelvic versus systemic compartments were the main descriptive parameters considered. The AUC was estimated using the linear trapezoidal method, whereas the maximum plasma concentration $\left(\mathrm{C}_{\max }\right)$ was taken as the maximum drug concentration (Table 4). Table 4 also reports median $\mathrm{pH}$ and $\mathrm{pO}_{2}$ values. Pharmacokinetic parameters were also calculated in peripheral blood samples (Table 5) as: the volume of distribution (Vd); elimination half-time $\left(\mathrm{T}^{1 / 2}\right)$; and total drug clearance $(\mathrm{Cl})$. The median and IQR percentage TMR values in blood exiting patients during hemofiltration (20 to $80 \mathrm{~min}$ ) were 26.8 (IQR 25.2 to 28.1 ) in the 5 surgical patients and 28.3 (IQR 26.9 to 29) in the 5 patients subjected to the percutaneous procedure, which were not significantly different $(p=0.465)$. Therefore, based on data reported in Tables 4, 5, the surgical and percutaneous procedures did not exhibit significant differences.

\section{Tolerability and procedure-related complications}

During the 10 procedures, no technical, hemodynamic, or vascular complications were encountered and femoral vessel cannulation was always achieved. Two cases of

Table 4 Comparison of the two techniques during the IPP (20 min) based on pharmacokinetic and biochemical parameters

\begin{tabular}{|c|c|c|c|c|c|}
\hline \multirow[t]{2}{*}{ Technique } & \multicolumn{2}{|l|}{ Surgical } & \multicolumn{2}{|c|}{ Percutaneous } & \multirow{2}{*}{$\begin{array}{l}\text { MW } \\
\text { p value }\end{array}$} \\
\hline & Median & IQR & Median & IQR & \\
\hline$C_{\max }$ perfused compartment $(\mu \mathrm{g} / \mathrm{ml})$ & 8.8 & (7.3 to 8.8$)$ & 7.4 & $(5.6$ to 7.8$)$ & 0.346 \\
\hline$C_{\max }$ perfused compartment $/ C_{\max }$ peripheric compartment & 7.8 & $(6.2$ to 8.4$)$ & 6.6 & (5 to 7.5$)$ & 0.602 \\
\hline$A \cup C_{0 \text { to } 20}$ perfused compartment $/ A \cup C_{0}$ to 20 peripheric compartment & 7.9 & (7.2 to 9.9$)$ & 5 & (4 to 7.9$)$ & 0.209 \\
\hline pH extracorporeal circuit & 7.39 & (7.38 to 7.39$)$ & 7.38 & (7.38 to 7.39$)$ & 0.656 \\
\hline $\mathrm{pO}_{2}$ extracorporeal circuit $(\mathrm{mmHg})$ & 29.41 & (28.56 to 29.64 ) & 29.64 & (29.51 to 29.67 ) & 0.248 \\
\hline
\end{tabular}

$M W$ Mann-Whitney test, $C_{\max }$ maximum plasma concentration, $A U C_{0 \text { to } 20}$ area under the plasma concentration curve ( 0 to $20 \mathrm{~min}$ )

Table 5 Comparison of the two techniques during IPP ( $20 \mathrm{~min}$ ) plus hemofiltration $(60 \mathrm{~min})$ based on peripheral pharmacokinetic parameters

\begin{tabular}{|c|c|c|c|c|c|}
\hline \multirow[t]{2}{*}{ Technique } & \multicolumn{2}{|l|}{ Surgical } & \multicolumn{2}{|c|}{ Percutaneous } & \multirow{2}{*}{$\begin{array}{l}\text { MW } \\
\text { p value }\end{array}$} \\
\hline & Median & IQR & Median & IQR & \\
\hline$C_{\max }(\mu \mathrm{g} / \mathrm{ml})$ & 2.3 & (2 to 2.5 ) & 2.0 & (1.9 to 2$)$ & 0.084 \\
\hline$A \cup C_{0 \text { to } 80}\left(\mu \mathrm{g} /\left.\mathrm{m}\right|^{*} \mathrm{~min}\right)$ & 81.9 & (78.4 to 84.7 ) & 70.3 & (64.8 to 81.7) & 0.251 \\
\hline $\mathrm{T}_{1 / 2}(\min )$ & 13 & (11.5 to 14$)$ & 16 & (14 to 16.5 ) & 0.076 \\
\hline $\mathrm{Vd}[\mathrm{mg} /(\mu \mathrm{g} / \mathrm{ml})]$ & 6.5 & (5.7 to 6.9 ) & 8.6 & (7.7 to 10.2 ) & 0.075 \\
\hline $\mathrm{Cl}[\mathrm{mg} /(\mu \mathrm{g} / \mathrm{ml}) / \mathrm{min}]$ & 12.3 & (11.8 to 13.9$)$ & 15.8 & (13.8 to 15.9$)$ & 0.175 \\
\hline
\end{tabular}

MW Mann-Whitney test, $A U C_{0 \text { to } 80}$ area under the plasma concentration curve $(0$ to $80 \mathrm{~min}), T_{1 / 2}$ half-life of elimination phase, $V d$ volume of distribution, $C l$ total clearance (extracorporeal plus systemic) 
seroma and 1 case of lymphorrhagia were observed following the surgical procedure (associated with lymphadenectomy in 3 cases) and 1 case of inguinal hematoma was observed following the percutaneous procedure.

\section{HypoxicIPP with hemofiltration-related toxicity}

Two cases of grade 1 neutropenia were detected following the surgical procedure, according to the World Health Organization (WHO) criteria [23] and 1 case of grade 3 neutropenia was observed following the percutaneous procedure. Granulocyte colony-factor supportive therapy was administered to these patients.

Gastro-intestinal toxicity (grade 1 to 2), characterized by transient nausea, was observed in one surgical and two percutaneous patients. Local toxicity (scrotum edema and pain) was detected in 1 patient submitted for inguinal lymphadenectomy.

\section{Discussion}

IPP can be achieved by both surgical or percutaneous approaches. In the present study, we have compared the two methods in terms of pelvic drug concentrations. Pelvic melphalan concentrations were assessed in pelvic venous and systemic blood in order to evaluate differences in pelvic and systemic drug bio-availability during the perfusion phase with vascular block. Melphalan concentrations in systemic blood and ultrafiltrates were also assessed to determine the rate of drug eliminated during hemofiltration. A reliable comparison between surgical and percutaneous procedures was made only when the perfusion phase with extracorporeal blood circulation was exactly the same, with respect to blood flow.

The results obtained from our study show that the two methods did not significantly differ with respect to melphalan bio-availability in the perfused pelvic compartment ( $\mathrm{AUC}_{0}$ to 20 ratios). The median 5 (IQR 4 to $7.9)$ and mean $6.42(\mathrm{SD}=2.56)$ values for pelvic versus systemic melphalan $\mathrm{AUC}_{0}$ to 20 ratio in the 5 percutaneous IPP patients, were lower than those reported by Bonvalot et al. (mean $\pm \mathrm{SD}=14.1 \pm 6$ ) [13], for different doses, sampling times and leakage rates. The percutaneous approach had, however, the clinical advantage of a significantly lower hospitalization time, with earlier (4 days) discharge from hospital, illustrating a further advantage of the percutaneous procedure in terms of cost-effectiveness.

No significant differences in the two methods were observed with respect to tolerability, procedure-related complications and side-effects, and we confirm the data reported by van Ijken et al. [9] concerning the absence of left colon ischemia during hypoxic pelvic perfusion.
We stress, however, the importance of using the surgical approach in association with lymphadenectomy.

Due to the particular structure of the percutaneous material (Fig. 2), a higher aspiration pressure was generally required when compared to surgical procedure. This difference in aspiration pressure was constantly adjusted by the equipment in order to guarantee the same mean blood flow value in the extracorporeal circuit. Furthermore, instead of a combination of devices, a single integrated apparatus was used in this study to control perfusion and hemofiltration, as required by European safety legislation (93/42 EU directive).

The rationale behind the 20-min perfusion time used in our study, was based upon in vitro and in vivo studies clearly demonstrating that the cellular uptake of melphalan is rapid and reaches a plateau with $10 \mathrm{~min}$, indicating rapid saturation [20]. Perfusion was performed under conditions of hypoxia, which significantly enhances the efficacy of melphalan [19, 20, 24], with short-term hypoxia also lowering the risk of neo-angiogenesis [25]. Furthermore, both in vitro and in vivo studies have demonstrated that hypoxia-induced acidosis enhances the cytotoxic effects of melphalan by 2.5 to 3.5 -fold, probably by increasing cellular drug uptake $[19,20]$.

Slow flow perfusion was performed in order to reduce drug leakage and lower systemic toxicity, and an important relationship between flow and pressure was observed in the circuit [4]. Aortic pressure falls to $20 \mathrm{mmHg}$ following occlusion and progressively increases with the flow rate. At a flow rate of $100 \mathrm{ml} / \mathrm{min}$, pressure in the pelvic circuit approximates $40 \mathrm{mmHg}$, whereas at a flow rate of $350 \mathrm{ml} / \mathrm{min}$, pressure increases to $60 \mathrm{mmHg}$. The pelvic circulation is rich in collaterals, making complete isolation of the vasculature impossible, and increasing perfusion pressure increases drug leakage to the systemic circulation. Therefore, hemofiltration was performed as the protective measure over alternative methods $[13,15$, 26] immediately post pelvic perfusion, in order to lower the risk of systemic side effects. Median TMR in the venous blood during the hemofiltration (20 to $80 \mathrm{~min}$ ) was approximately $27.5 \%$.

\section{Conclusions}

No final conclusions can derive from this pilot study. In terms of tumor exposure to drug, the percutaneous approach for IPP did not statistically differ to the surgical procedure $(\mathrm{p}=0.209)$ at a perfusion blood flow rate of approximately 100 to $120 \mathrm{ml} / \mathrm{min}$. However, our preliminary results, concerning the pharmacokinetics variables, will be invaluable in the future planning of an 80 to $90 \%$ statistical power study. According to the ratio of the 
areas under the melphalan plasma concentration curves in pelvic and systemic compartments during the perfusion $\left(\mathrm{AUC}_{0}\right.$ to 20$)$, the total sample size should be adjusted to 60 patients, given a $90 \%$ power and $\alpha$-level of $5 \%$, and a future avenue of this research topic would be the further miniaturization of materials utilized for the percutaneous procedure.

\section{Additional file}

Additional file 1. All data detected are in additional file.

\begin{abstract}
Abbreviations
IPP: isolated pelvic perfusion; AUC: area under the curve; SD: standard deviation; Fr.: French; CT: computed tomography; HPLC: high-performance liquid chromatography; TMR: total melphalan removal; $C_{\text {max }}$ : maximum plasma concentration; $\mathrm{Vd}$ : volume of distribution; $\mathrm{T} 12 \mathrm{2}$ : half-time of elimination; $\mathrm{Cl}$ : clearance; WHO: World Health Organization; MW: Mann-Whitney test; VBA: Visual Basic for Applications.
\end{abstract}

\section{Authors' contributions}

In our study, SG MC, LM, AVG operated the patients, SG, GP, GF, MV participated in the design of the study, FM, MV performed the statistical analyses, SG, GP drafted of the manuscript. All authors read and approved the final manuscript.

\section{Author details}

1 Department of Applied Clinical Sciences and Biotecnology, University of L'Aquila, via Vetoio, 67100 L'Aquila, Italy. ${ }^{2}$ Department of Life, Health and Environmental Sciences, University of L'Aquila, via Vetoio, 67100 L'Aquila, Italy. ${ }^{3}$ Medical Oncology Unit, Department of Oncology and Hematology, Azienda Ospedaliera "Ospedali Riuniti Marche Nord", Pesaro, Italy.

\section{Acknowledgements}

We would like to thank Aigner Karl Reinhard for his surgical teaching and Mackay Andrew Reay for copyediting this article.

\section{Competing interests}

The authors declare that they have no competing interests.

\section{Availability of data and materials}

All data generated or analysed during this study are included in this published article and its Additional file.

\section{Consent for publication}

The manuscript does not contain any individual person data, so consent for publication is not applicable.

\section{Ethics approval and consent to participate}

This project has been performed in accordance with the Declaration of Helsinki and has been approved by the ethics committee of University of L'Aquila, L'Aquila, Italy. Written informed consent was obtained from each of the 10 patients.

\section{Funding}

No funding was received.

\section{Publisher's Note}

Springer Nature remains neutral with regard to jurisdictional claims in published maps and institutional affiliations.

Received: 13 January 2017 Accepted: 7 August 2017

Published online: 15 August 2017
References

1. Klopp CT. Regional intra-arterial nitrogen mustard as an adjunct to radiation therapy. Am J Roentgenol Radium Ther Nucl Med. 1953;70:1005-14.

2. Creech $\mathrm{O}$, Krementz ET, Ryan RF, et al. Chemotherapy of cancer: regional perfusion utilizing an extracorporeal circuit. Ann Surg. 1958;148:616-32.

3. Watkins E Jr, Hering AC, Luna R, et al. The use of intravascular balloon catheters for isolation of the pelvic vascular bed during pump-oxygenator perfusion of cancer chemotherapy agents. Surg Gynecol Obstet. 1960;111:464-8.

4. Begossi G, Belliveau JF, Wanebo HJ. Pelvic perfusion for advanced colorectal cancers. Surg Oncol Clin N Am. 2008;17:825-42.

5. Guadagni S, Aigner KR, Palumbo G, et al. Pharmacokinetics of mitomycin $C$ in pelvic stopflow infusion and hypoxic pelvic perfusion with and without hemofiltration: a pilot study of patients with recurrent unresectable rectal cancer. J Clin Pharmacol. 1998;38:936-44.

6. Aigner KR, Kaevel K. Pelvic stopflow infusion (PSI) and hypoxic pelvic perfusion (HPP) with mitomycin and melphalan for recurrent rectal cancer. Reg Cancer Treat. 1994;7:6-11.

7. Turk PS, Belliveau JF, Darnowski JW, et al. Isolated pelvic perfusion for unresectable cancer using a balloon occlusion technique. Arch Surg. 1993;128:533-9.

8. van Ijken MG, van Etten B, Guetens G, et al. Balloon catheter hypoxic abdominal and pelvic perfusion with tumor necrosis factor-alpha, melphalan and mitomycin C: a pharmacokinetic study in pigs. Eur J Surg Oncol. 2004;30:699-707.

9. van ljken MG, van Etten B, Guetens $G$, et al. Balloon catheter hypoxic pelvic perfusion with mitomycin $C$ and melphalan for locally advanced tumours in the pelvic region: a phase I-II trial. Eur J Surg Oncol. 2005;31:897-904.

10. Thompson JF, Waugh RC, Kam P. Stop-flow cytotoxic infusion. A simplified technique using percutaneous catheters. Reg Cancer Treat. 1993;6(Suppl 1):51.

11. Thompson JF, Liu M, Waugh RC, et al. A percutaneous aortic "stop-flow" infusion technique for regional cytotoxic therapy of the abdomen and pelvis. Reg Cancer Treat. 1994;7:202-7.

12. Ricci S, Rossi G, Roversi R, et al. Antiblastic locoregional perfusion with control of the aorto-caval flow: technique of percutaneous access. Radiol Med. 1997;93:246-52

13. Bonvalot $\mathrm{S}$, de Baere T, Mendiboure J, et al. Hyperthermic pelvic perfusion with tumor necrosis factor-a for locally advanced cancers. Encouraging results of a phase II study. Ann Surg. 2012;255:281-6.

14. Murata S, Onozawa S, Kim C, et al. Negative-balance isolated pelvic perfusion inpatients with incurable symptomatic rectal cancer: results and drug dose correlation to adverse events. Acta Radiol. 2014;55:793-801.

15. Guadagni S, Russo F, Rossi CR, et al. Deliberate hypoxic pelvic and limb chemoperfusion in the treatment of recurrent melanoma. Am J Surg. 2002;183:28-36.

16. Guadagni S, Santinami M, Patuzzo R, et al. Hypoxic pelvic and limb perfusion with melphalan and mitomycin C for recurrent limb melanoma: a pilot study. Melanoma Res. 2003;13:51-8.

17. Balch CM, Gershenwald JE, Song SJ, et al. Final version of 2009 AJCC melanoma staging and classification. J Clin Oncol. 2009;27:6199-206.

18. Schag CC, Heinrich RL, Ganz PA. Karnofsky performance status revisited: reliability, validity, and guidelines. J Clin Oncol. 1984;2:187-93.

19. Pruijn $F B$, van Daalen $M$, Holford NH, et al. Mechanisms of enhancement of the antitumour activity of melphalan by the tumour-blood-flow inhibitor 5,6-dimethylxanthenone-4-acetic acid. Cancer Chemother Pharmacol. 1997;39:541-6.

20. Kam PCA, Thompson JF. Pharmacokinetics of regional therapy: isolated limb infusion and other low flow techniques for extremity melanoma. Surg Oncol Clin N Am. 2008;17:795-804.

21. Mirkou A, Vignal B, Cohen S, et al. Assay for the quantification of melphalan and its hydrolysis products in human plasma by liquid chromatography-tandem mass spectrometry. J Chromatogr B Anal Technol Biomed Life Sci. 2009;877:3089-96.

22. Zhang Y, Huo M, Zhou J, Xie S. PKSolver: an add-in program for pharmacokinetic and pharmacodynamic data analysis in Microsoft Excel. Comput Methods Progr Biomed. 2010;99(3):306-14. 
23. World Health Organization. WHO Handbook for Reporting Results of Cancer Treatment. Geneva, Switzerland: World Health Organization; 1979. WHO offset publication No. 48.

24. de Wilt JH, Manusama ER, van Tiel ST, et al. Prerequisites for effective isolated limb perfusion using tumour necrosis factor alpha and melphalan in rats. Br J Cancer. 1999;80:161-6.
25. Fiorentini G, Cantore M, Montagnani F, et al. The role of hypoxia and hyperthermia in chemotherapy. In: Aigner KR, Stephens FO, editors. Induction chemotherapy. Systemic and locoregional. Berlin: SpringerVerlag; 2016. p. 61-71.

26. Lawrence $W \mathrm{Jr}$, Kuehn P, Mori S, et al. Regional perfusion of the pelvis: consideration of the "leakage" problem. Surgery. 1961;50:248-59.

\section{Submit your next manuscript to BioMed Central and we will help you at every step:}

- We accept pre-submission inquiries

- Our selector tool helps you to find the most relevant journal

- We provide round the clock customer support

- Convenient online submission

- Thorough peer review

- Inclusion in PubMed and all major indexing services

- Maximum visibility for your research

Submit your manuscript at

www.biomedcentral com/submit 